\title{
Planning Metropolitan Scenarios for the Strait Area
}

\author{
Concetta Fallanca ${ }^{1, a}$ \\ ${ }^{1}$ Mediterranea University of Reggio Calabria - PAU - Department of Heritage, Architecture, Urban \\ Planning, Via Salita Melissari - 89124, Reggio di Calabria, Italy \\ acfallanca@unirc.it
}

Keywords: Urban Civilization, Metropolitan Performances, Territorial Identity, Urban Planning, Reduction of Vulnerability.

\begin{abstract}
The common thread that links Reggio and Messina can be intended for the two cities to grow stronger and tie, with the alliance of Villa San Giovanni, moving towards advanced urban quality and performance. Time seems ripe to fulfill set evoked forty-five years ago with Project 80 for a new type of urban civilization towards a metropolitan scale because only high urban ranks could be considered able to provide goods and services that belong to a civilized society.

The irresistible charm the City on the Strait has, is probably due to an extraordinary liquid significance to be considered as a primary infrastructure.

The City of the Strait is not to be seen as a city that gets bigger, or two or three cities that become one; it is a city with solid and liquid ways, with significant urban parts that also interact visually, that wisely integrate and re-know in a richer and more complex territorial identity.

The growing presence of the territorial risk dimension has to push for the need to innovate the forms and practices of urban planning, basing the plans and the projects for the city on risk prevention, building to offer itself to the widest dimension of the Mediterranean basin as a privileged point of observation about seismic hazard assessment.
\end{abstract}

\section{Introduction}

Standing on any of the four white towers' terrace, identifying from Reggio Calabria, by now for years the Mediterranean University and stretching out to the Strait, is possible to enjoy a privileged point of observation from the calabrian coast.

This is a place which attracts look towards a wide horizon, ever-changing, which goes from Punta Calamizzi, with a special background like the Volcano Etna is, to Capo Peloro and further to north with the coast of the Piana that brighten, improving nobility carat, even when the sky is clear.

From the top of these towers the breath of the Strait is shared, all the winds can be felt and violent vibrations can be perceived in the exaltation of the most innocuous seismic jolt. The energy of the Straight can be perceived: it changes as soon as the seasons do, and sometimes it suddenly changes even during the same day and that is by the hour in an unpredictable way revealed. The island light that makes the water iridescent and clear urban background can turn into dark tones in a few minutes, moving away the next city in a gloomy and suddenly hostile city landscape.

In the Strait everything thickens, the meanings follows themselves, multiply themselves, overlap themselves in a kind of Aleph that according to what Jorge Luis Borges says [1], is one of the points of the space that contains all the points: there is a vortex between these waters that is the place where they find themselves, voiding to get confused, all the points of the earth, seen from all the angles. Surely the Strait guards, in its deep waters, a small shimmering sphere, in a almost intolerable heyday that seems to rotate although the movement is an illusion produced from the breathtaking shows that it encloses.

This, like the Aleph in the Borges' cellar, though not exceeding the diameter of two or three centimeters contains outer space, voiding the vastness to suffer. Anything is everything because things can be clearly seen from all the points of the universe. Ancient mansions can be seen, austere cathedrals can be seen, proud castles can be see; wise triangulations shored up by watchful towers can be seen, river ports and primigenial forests. 
Eroded beaches and squares of the mesa can be seen, terraced slopes, wooden huts, destroyed cities and stubbornly rebuilt can be seen. Feluche with high faleri and the docks can be see, cranes, scaffolding and shrines can be seen, gulls, pittosporum bushes, armacere and vineyards can be seen. Towering snow-capped peaks topped with puffs of steam and crossed by streams of lava can be seen, currents such as cross-rivers, seas staircases that meet, eddies, whirlpools and the Sickle's City hemming the horizon can be seen.

Other stories, other narrow corridors of ancient migration routes of birds that ply on the Mediterranean sea can be seen. This extremely intense emotional field contains everything and its opposite, in space and time; it encloses lofty quality and lowly degradation, archaic values and wonderful innovations. It must be, that density of events, the fate of the Straits, power and vulnerability landscapes where the dialogue between land and sea looks more fertile than elsewhere. Where the waters take on an anthropomorphic meaning and rituals associated with them are experienced as elective affinities.

I saw, many years ago, Predrag Matvejevic gets wet hands, look up a contact, caressing the waters of our Strait with the same gestures that I myself had done once I first met other waters: in the Bosphorus, in the Golden Horn, in the Strait of Gibraltar, into the Atlantic Ocean, in the Tagus, in the Nile, in the canals of Amsterdam, on the shore of the Jordan, in the Black Sea. We both smiled thinking to Xerxes that whipped the haughty waters of Hellespont sea, the Dardanelles, guilty of having destroyed, impetuous, the bridge of boats that was being made for his army's transit.

In recent history the Strait of Scilla and Cariddi is back to being crossed as in ancient times by a long course of trade and these waters are crossed more and more frequently by cruise ships bound for Naples, Livorno, Genova and transhipment vessels that deliver in port of Gioia Tauro goods also directed to northern Italy and central Europe.

In a sense, the Strait becomes international again, regains its former centrality in the Mediterranean Sea and the two border cities, Reggio Calabria and Messina, that in national and regional contexts have unique identities and specifically differentiated, become in the Mediterranean context an interesting and complex reality which is characterized in the Strait.

The analogies and the differences that by myths, legends, history and culture characterize the two sides of the Strait where the urban sets of Rhegion and Zancle take to form and in both the score of the infinite variations on the city topic is orchestrated by unrepeatable episodes and processes of a long period, individual choices and collective pressures.

The common thread that links Reggio and Messina that, in the past, seems to have mainly concerned the dramatic urban events, can be intended for the two cities to grow stronger and tie moving towards advanced urban quality and performance [2].

A broad look at what has been, in the history of their territorial roles gives the impression that they have had alternate success, that a glamorous period of one has seen the other decadent in a sort of threshold that fixes mysteriously, but trough a full compliance with the logic of competitiveness, total urban quality.

\section{The irresistible charm of the City of the Strait}

Time seems ripe to fulfill set evoked forty-five years ago, when enlightened planners like Paolo Iacobelli, Gian Ludovico Rolli, understood as in the future of these lands metropolitan scenarios were shown. In the seventies with the Project 80 and then in the eighties with the Strategic Project Quadroter an interesting way for the development of a national strategic framework for planning had been outlined.

It is useful to remember that the official document of the Project 80 evoked «a new kind of urban civilization» which involved «the recognition of the need for urban evolution towards metropolitan scale because it was believed that only a few urban ranks were able to provide citizens with the goods and services that belong to a civilized society». A new kind of urban civilization to be obtained through a process of balanced approach «inside every urbanized area and in the relationships between the several areas» (Project 80: Preliminary relationship to national economic Program 1971-1975, Roma April 1969). 
Visions confirmed by Alessandro Bianchi and Manlio Vendittelli [3], boosted by Francesco Archibugi [4] and defended over the time by Osvaldo Pieroni [5], Nuccio Barillà, Alberto Ziparo and Tonino Perna, Councilor for Culture of the City of Messina, in full harmony with Renato Accorinti, a mayor with creative ideas who invesions and proposes and pursues shared projects between the two sides.

The Calabrian side includes more and more often Messina in Reggio planning too; in the last year, on the initiative of the Prefect Vittorio Piscitelli, a committee of scholars, researchers, experts, of which I myself writing am member, has worked on the construction of three projects designed to Reggio metropolitan city and evidently facing the metropolitan area of the Strait.

The first project proposes the creation of a Historical Literary Park to complement the experience of the literary park Horcinus Horca that mainly generated effects and activities in the island side with little impact on the mainland. A Literary Park aims to strengthen the system of cultural tourist attractions of which the Museum of Magna Grecia in Reggio Calabria is the main magnet, exploring and «valuing a literary tradition that develops over a period of twenty-five centuries, from poets magnogreci to the authors meridionalisti of twentieth century».

The second project involved the path that led to the nomination of Reggio Calabria as a European Capital of Culture for the year 2019, which allowed beyond the outcome - that excluded from preset the city, together with as good cities as Mantova, Palermo, Urbino, Venezia, in favor of Cagliari, Lecce, Matera, Perugia, Ravenna, Siena, which compete for the role - convergence and sharing between different agencies towards a systematic complex of cultural events and activities of great impact, with the assumption of commitments to financing which could provide a self-realization. Also in this case the membership area of the Strait, starting from the potential that this encloses, was taken as the fundamental value in support of the aspirations of Reggio.

The third project is creating a new link between Reggio Calabria, Messina and Villa San Giovanni with the proposed inclusion of the area of the Strait in the group of Italian sites included in the "World Heritage List" in accordance with Law 77/2006, application of the Convention UNESCO for the preservation of cultural and natural World Heritage, signed in Paris in November 1972. In this case too, the value of the path is much larger than the result achieved, although a recognition would represent a huge opportunity for the image area revival providing the ability to attract interest and national and international funding; the initiative is creating, however, an agreement profitable and a new partnership between the three cities.

Two urban realities, then, of medium size and a third still more restrained, which have a modest attractiveness and essentially provincial character, are pointing now to contribute to a common project, the rooting of the City of the Strait, which already appears to a wider look, International, Mediterranean, Europe. The intensity of the exchanges between the two sides is the same intensity that supports the consolidation of the City of the Strait. The relationship between Messina and Reggio Calabria are vital in a metropolitan dimension that offers a whole service of collective interest such as the universities, the Academy of Fine Arts, theaters, libraries, museums, health centers, the airport, the Horcynus Orca literary park by Stefano d'Arrigo [6].

The geographical area of the Strait, with the cities of Reggio, Messina, Villa San Giovanni, with a potential of five hundred thousand inhabitants, and a million and two hundred inhabitants from both provinces, presents homogeneous characters for geo-morphological and environmental structure, with significant common elements for what concerns the historical development, the settlement and the chronological and territorial contiguity of phenomena that have taken place. They share the culture of coexistence with the seismic risk, homogeneous economic and social characteristics, which allow the identification of territorial needs and shared objectives, to be achieved in practice through the development of an integrated urban-territorial planning.

Is quite a long time now that the LASTRE - Laboratory of integrated research on the area of the Strait of Mediterranean University of Reggio Calabria works, aiming to create an integrated network of research centers and institutions cooperating inside of the area of the Strait on the issues related to the transformation of the city and the territory meant in its broadest sense, optimizing the management of information and facilitating, through the network, the fruition. This objective aims to 
ensure a high level of interoperability between the parties identified for the establishment of the network with the aim to facilitate the sharing of information, contents and services between a plurality of public and private subjects, working on areas for which a clear convergence of local institutions involved is expressed.

When aiming to simplify the relations between the two sides of the Strait and do not discard the results of numerous studies already carried out, it is necessary to intervene in the processes involved in the exchange of information between public and private actors involved, reorganizing and integrating them to provide, in the areas identified, the convergence of information and the development of research to void starting back again, for each new initiative, from basic studies. The section of the Observatory for the "integrated Area of the Strait" has among its strategic objectives the optimization of mobility systems, networking of tourism potential of the two areas with the creation of joint themed itineraries, a program of internationalization of tangible and intangible events and especially the differentiation and integration of supply of local services in the cultural, environmental, tourism and manufacturing fields. It aims at a high-profile project that combines the links efficiency and integration with an intelligent system of planned and agreement reception for the exploitation of the rich natural and cultural heritage. This is therefore placed in a context of life and urban uses established consisting of exchanges and interconnections, organizational and economic needs, and in a situation in which the design vitality has focused its attention to the issue of stable connection diverting them from seeking other forms of solution as a serious, efficient integrated system of sea routes.

To wonder with Joseph Rykwert: from where the irresistible fascination of some cities is born? From where the uneasiness alienor of many others is given off? Which are the factors determining the fate? Reflect on these issues can feed the value of the quality of the project. The irresistible charm of the City of the Strait concentrates on extraordinary liquid significance that fills the Strait and that is offered as a primary infrastructure.

The City of the Strait is not to be seen as a city that gets bigger, or two or three cities that become one; it is a city with solid and liquid ways, with significant urban parts that also interact visually, that wisely integrate and re-know in a richer and more complex territorial identity.

Feeling citizen of the Strait is a mental condition; it is a feeling of belonging to a place of peculiar and extraordinary container of nature, culture and human relationships but at the same time a place that today needs, much more than others, acts of qualifying exploitation.

A prerequisite to any qualifying action relates to the efficiency and fluidity of accessibility, connectivity, mobility between conspicuous places on both shores. Frequency of connections, accessibility from any point of view and efficient coverage within 24 hours, encourage "complementary" use of cultural, educational, healthcare, commercial offers of the two cities. These performances are fundamental to the creation of the metropolitan city of the Strait at the base of the project, shared and pursued by the two banks, enhancement of the nature, culture, human relationships network, in order to foster a relationship between most important cities and territories of the two provinces.

\section{Planning lands in motion}

For the city of Reggio, Messina and Villa San Giovanni, for the "City of the Strait", the deep need to include, in the total project of metropolitan city formation, the strategic issue of seismic risk prevention is strongly felt.

A look at the past shows that in the field of seismic hazard, of exposure to these events, in the relationship between natural disaster and social life, features of an ancient and the same time very current culture can be discerned between the two cities: the coexistence culture with the earthquake, which once was and could, should, go back to being a culture of prevention and not of removal of the risk, of the unexpected, of the chaotic.

The perpetuation of natural disasters affecting these places consistently highlights the physical and structural fragility of the city and urban spaces, but still, from time to time also seems to delete the 
collective memory and above all in the absolute lack of appropriate strategies useful to cope with these problems.

The growing presence of the territorial risk dimension has to push for the need to innovate the forms and practices of urban planning, basing the plans and the projects for the city on risk prevention.

Some of the more recent experiences developed in Abruzzo after the 2009 earthquake and the one in Emilia after 2012 with «the laboratories participated of prevention seismic damage» (Ferrara), just to mention a few Italian examples, led to consolidate the essential underlying principles which should be guided by the strategies of planning under risk conditions, based on the awareness that the issue of urban security, understood in the sense of physical safety of urban places, is intertwined with the issues that arise from the changes taking place in our cities.

Moreover, there is no doubt that a new paradigm of urban regards the prevention of risks, even experimenting with the extensive research on urban seismic vulnerability. Researches from which we have learned the need for intervention to the zoning regulations as well as the theme of the building seismic safety, but also learned the need to promote and enable innovative forms of participation that aim to the prevention of seismic activity.

A workshop of "prevention for safety" where to start thinking more focused on the relationship between risk and quality of urban design; where to promote programs and policies that can be put in place to protect the environment and the urban habitat from the effects of a natural disaster; where to experiment the ability to use the contingency of calamitous danger to improve techniques and area planning quality.

Finally, a laboratory in which to enable monitoring networks, surveys and in which to promote training and information campaigns aimed at the population to acquire the appropriate theoretical and practical knowledge to reduce vulnerability to seismic risk.

Living with the seismic hazard can be worth to search the formal and substantive quality of the spaces that here, more than in other places, highly performative values have to be expressed to build a sense of security and prudent prevention for a society that, in a further another act love has renewed his choice of settlement site.

For our Strait is easy to share deep feelings that Orhan Pamuk [7] devotes to the Bosphorus Strait: the Strait is for me a source of endless hope and optimism, which takes up the life of the city and gives health and refreshment to men.

\section{References}

[1] J. L. Borges: L'Aleph, Adelphi (2002)

[2] L. Gambi: Da città ad area metropolitana in Storia d'Italia, Volume V, Einaudi (1973)

[3] A. Bianchi, M. Vendittelli: L'attraversamento dello Stretto, Casa del Libro Editrice (1982)

[4] F. Archibugi: Gli obiettivi strategici del Progetto 80 e il Quadro territoriale di riferimento, in Dal Progetto 80 all'Italia che verrà, Ministero delle Infrastrutture, Roma, 20 Febbraio 2007

[5] O. Pieroni: Tra Scilla e Cariddi. Il Ponte sullo Stretto di Messina: ambiente e società sostenibile nel mezzogiorno, Rubettino (2000)

[6] N. Aricò: Illimite Peloro: interpretazioni del confine terracqueo, Mesogea (1999)

[7] O. Pamuk: Istanbul, Einaudi (2006) 